\title{
Bacteriological Profile of Endotracheal Aspirates from Patients with Lower Respiratory Tract Infections and Their Antibiotic Resistance Pattern
}

\author{
Aishwarya Dilip Warangํㅗ , Sharvari Amol Samant ${ }^{2}$ \\ 1, 2 Department of Microbiology, MGM Medical College and Hospital, \\ Kamothe, Navi Mumbai, Maharashtra, India.
}

\section{ABSTRACT}

\section{BACKGROUND}

Lower respiratory tract infections (LRTI) in mechanically ventilated patients are associated with high mortality and morbidity. Therefore, identification of the causative agents and their antibiotic susceptibility pattern play a key role in selecting the suitable antibiotics thus improving the condition of the patient. We wanted to study the bacteriological profile of endotracheal aspirate from patients with LRTI and their antibiotic resistance pattern.

\section{METHODS}

A total of 100 samples of endotracheal aspirates from patients with LRTI was cultured as per standard microbiological technique. Organisms were identified and antibiotic resistance pattern was studied. The gram-negative isolates were subjected for detection of extended spectrum beta lactamase (ESBL) and metallo beta lactamase (MBL). Methicillin resistance was checked for $S$. aureus as per Central Laboratory Standard Institute (CLSI) guidelines.

\section{RESULTS}

In this study acinetobacter species (27.3\%) and klebsiella species (27.3\%) were the predominant organisms that were multidrug resistant. Extended spectrum $\beta$ lactamase production was reported in $78.12 \%$ of klebsiella species, $66.67 \%$ of $E$. coli, $50 \%$ of acinetobacter spp and $37.5 \%$ of citrobacter species; MBL production was detected in $57.14 \%$ of P. aeruginosa. A total of $26 \%$ S. aureus isolates were methicillin resistant.

\section{CONCLUSIONS}

Multi drug resistance was significantly high within the strains isolated from endotracheal (ET) secretions of LRTI patients. Majority of the MDR strains were ESBLs or MBLs producing gram negative bacilli (GNBs) or methicillin resistant $S$. aureus.

\section{KEY WORDS}

Lower Respiratory Tract Infection, Endotracheal Aspirate, Extended Spectrum $\beta$ Lactamase, Metallo $\beta$ Lactamase, Methicillin Resistant Staphylococcus aureus
Corresponding Author: Dr. Sharvari Amol Samant, Department of Microbiology, MGM Medical College, Sector 1, Kamothe, Kalamboli - 410209, Navi Mumbai, Maharashtra, India.

E-mail: savysamant@gmail.com

DOI: $10.14260 /$ jemds/2021/79

How to Cite This Article: Warang AD, Samant SA. Bacteriological profile of endotracheal aspirates from patients with lower respiratory tract infections and their antibiotic resistance pattern. I Evolution Med Dent Sci 2021;10(06):352-356, DOI: 10.14260/jemds/2021/79

Submission 21-09-2020,

Peer Review 08-12-2020,

Acceptance 15-12-2020,

Published 08-02-2021.

Copyright (C) 2021 Aishwarya Dilip Warang et al. This is an open access article distributed under Creative Commons Attribution License [Attribution 4.0 International (CC BY 4.0)] 


\section{BACKGROUND}

Ventilator associated pneumonia (VAP) is a sub-type of hospital acquired pneumonia (HAP) occurring in patients who are receiving mechanical ventilation (MV) for at least 48 hours or more. Although it is a lifesaving procedure for the hospitalised patients its severe drawback is acquiring persistent LRTI leads to high mortality and morbidity rate in patients.

Lower respiratory tract infection is outlined because of the inflammation of the respiratory tract ranging from trachea to the alveoli with sequent multiplication of an infectious agent. Patients who are on mechanical ventilation for a minimum of 48 hours or additional are at a risk of acquiring persistent LRTI resulting in serious health touching issues in patients worldwide. For the effective treatment of LRTI in patients, precise information of microbial investigation, higher and better diagnostic practices and antimicrobial susceptibility pattern are extremely important.

LRTI mainly in developing countries the common cause of infection among patients is pneumonia. LRTI is caused when patients are colonised with bacteria of either exogenous or endogenous origin. Colonisation in lower respiratory tract by gram negative bacteria have been frequently observed in patients after tracheostomy and patients with persistent trachea bronchial colonisation. The type of LRTI depends on various factors viz. epidemiology, pathogenesis and host response. The major respiratory pathogens are gram negative bacilli like Klebsiella pneumoniae, Escherichia coli, Pseudomonas aeruginosa, acinetobacter species, other nonfermentative gram-negative bacilli (NFGNB) and grampositive organisms like Streptococcus pneumonia, Staphylococcus aureus etc.

The endotracheal aspirate from patient with LRTI is collected for microbiological and cultural diagnosis of LRTI. As it is easily performed at bedside and is totally simple, cheap and minimally invasive, it also has a proven acceptable precision and requires minimal speculation for the training of health professionals. ${ }^{1}$ Multi drug resistant gram-negative bacteria are the foremost reason for concern in LRTI. Although it is a lifesaving procedure for the hospitalised patients it has a severe drawback of acquiring persistent LRTI leading to high mortality and morbidity rate in patients. The patient who had been intubated, their endotracheal tube aspirate was collected and was processed by standard methods. Many organism's including multiple drug resistant organism are responsible for causing ventilator associated pneumonia.

The misuse of antibiotics is considered as a direct cause of antibiotic resistance worldwide. ${ }^{2}$ Multi drug resistance in GNBs may be related to enzymes like extended spectrum beta lactamase (ESBL) or metallo beta lactamase (MBL). Amongst staphylococci, methicillin resistance can be the cause for multi-drug resistance. The antimicrobial therapy for LRTIs is frequently empirical and presumptive. To study the current pattern of the organism causing LRTI, specific microbiological investigations are necessary for proper identification of causative organisms and their antibiotic susceptibility profile. Therefore, the current study was planned to study the bacteriological profile of endotracheal aspirates of hospitalised patients with LRTI and to check the antibiotic resistance pattern with special relevance to ESBL and MBL production in gram negative bacteria and methicillin resistance in Staphylococcus aureus.

\section{METHODS}

This is a hospital based, cross-sectional study carried out for a period of 2 years from October 2017 to March 2019 in the Department of Microbiology of MGM Medical College and Hospital after the approval from institutional ethics committee. The endotracheal aspirate (ETA) from patients with lower respiratory tract infections was collected by a trained respiratory therapist by non-bronchoscopic technique and processed immediately.

The ETA sample was immediately inoculated on blood agar, MacConkey's agar and the plates were incubated at $37^{\circ} \mathrm{C}$ for 24 hours. The clinical isolates were identified, and antibiotic sensitivity was performed on Muller-Hinton agar plates by Kirby Bauer's disc diffusion method using suitable antibiotics as per CLSI guidelines. ${ }^{3}$

\section{Test for ESBL Detection ${ }^{4}$}

\section{Screening Test}

ESBL test was performed by using antibiotics like cefotaxime and ceftazidime on Muller-Hinton agar plates. Zone size less than $20 \mathrm{~mm}$ for cefotaxime and ceftazidime was screened positive for ESBL. The strains found to be ESBL screen positive were subjected to phenotypic confirmatory tests.

\section{Phenotypic Confirmatory Test}

The discs of ceftazidime (CAZ-30 $\mu \mathrm{g}$ ) and ceftazidime with clavulanic acid (CAC-30 / $10 \mu \mathrm{g}$ ) and cefotaxime (CTX-30 $\mu \mathrm{g}$ ) and cefotaxime-clavulanic acid (CTX-30 $\mu \mathrm{g})$ were placed on MHA plate and incubated at $37^{\circ} \mathrm{C}$ overnight. Increase in zone size by $\geq 5 \mathrm{~mm}$ with ceftazidime / clavulanic acid and cefotaxime-clavulanic acid in comparison to ceftazidime or cefotaxime alone, then the strain is confirmed to be an ESBL producer.

\section{Test for MBL Detection ${ }^{4,5}$}

MBL production was detected in imipenem resistant isolates by phenotypic tests. The imipenem (IMP) EDTA combined disc test was used. Test organisms were inoculated on to plates of Muller Hinton agar as recommended by CLSI. ${ }^{4}$ In the combined disc test, increase in inhibition zone with the imipenem and EDTA disc is $\geq 7 \mathrm{~mm}$ than the imipenem disc alone, it is considered as MBL positive. ${ }^{5}$

\section{Test for MRSA Detection ${ }^{4}$}

Methicillin resistance was detected by using a cefoxitin disc $(30 \mu \mathrm{g})$. Plates were incubated at $35^{\circ} \mathrm{C}$ for $24 \mathrm{hrs}$. Results were interpreted according to CLSI, a zone of growth inhibition 
around cefoxitin disk $\geq 22 \mathrm{~mm}$ rules out MRSA; a zone size < $22 \mathrm{~mm}$ indicates MRSA.

\section{Statistical Analysis}

All the results were analysed statistically. Level of significance was set at 0.05 . All $P$ values $>0.05$ were considered significant.

\section{RESULTS}

Out of 1,440 ET secretions of clinically suspected lower respiratory tract infection patients, 100 cases were enrolled for this project. All the 100 samples yielded mono or polymicrobial growth. A total of 117-gram negative bacteria and 38-gram positive bacteria were isolated during this study. It was observed that acinetobacter spp and klebsiella spp were the foremost predominant isolates (27.3\% each) followed by Pseudomonas aeruginosa (17.6\%). Amongst 38 gram positive isolates, the foremost predominant was Staphylococcus aureus (50\%).

\begin{tabular}{|c|c|c|c|}
\hline & & No. of Isolates & Percentage \\
\hline \multirow{7}{*}{$\begin{array}{c}\text { Gram negative } \\
\text { bacteria }\end{array}$} & Acinetobacter spp & 32 & $27.3 \%$ \\
\hline & Klebsiella spp & 32 & $27.3 \%$ \\
\hline & P. aeruginosa & 21 & $17.6 \%$ \\
\hline & Citrobacter spp & 11 & $9.4 \%$ \\
\hline & E. coli & 9 & $7.6 \%$ \\
\hline & Enterobacter spp. & 9 & $7.6 \%$ \\
\hline & GNNF & 3 & $2.5 \%$ \\
\hline \multirow{3}{*}{$\begin{array}{c}\text { Gram positive } \\
\text { bacteria }\end{array}$} & Staphylococcus aureus & 19 & $50 \%$ \\
\hline & $\begin{array}{l}\text { Coagulase negative } \\
\text { Staphylococcus aureus } \\
\text { (CONS) }\end{array}$ & 9 & $23.6 \%$ \\
\hline & Streptococcus spp & 9 & $23.6 \%$ \\
\hline \multicolumn{4}{|c|}{$\begin{array}{l}\text { Table 1. Spectrum of Gram-Negative Bacteria and } \\
\text { Gram-Positive Bacteria Isolated in ET Secretions }\end{array}$} \\
\hline
\end{tabular}

\begin{tabular}{|c|c|c|}
\hline Organism & $\begin{array}{c}\text { Antibiotics Showing } \\
\text { Maximum Resistance to }\end{array}$ & $\begin{array}{c}\text { Antibiotics Showing } \\
\text { Minimum Resistance to }\end{array}$ \\
\hline Acinetobacter spp & $\begin{array}{l}\text { Ceftazidime }(96.8 \%) \\
\text { Cefoperazone }(93.7 \%) \\
\text { Cefazolin }(90.6 \%)\end{array}$ & $\begin{array}{c}\text { Amikacin }(34.3 \%) \\
\text { Ofloxacin }(37.5 \%) \\
\text { Levofloxacin }(3.1 \%) \\
\text { Polymyxin B }(3.1 \%) \\
\text { Tigecycline }(9.3 \%)\end{array}$ \\
\hline Klebsiella spp & $\begin{array}{c}\text { Tetracycline, }(90.6 \%) \\
\text { Cefuroxime }(87.5 \%) \\
\text { Ceftazidime }(84.3 \%) \text { Ticarcillin / } \\
\text { Clavulanic acid }(65.6 \%) \\
\text { Cefixime / Clavulanic acid }(56.2 \%) \\
\text { Aztreonam (50\%) }\end{array}$ & $\begin{array}{l}\text { Amikacin }(15.6 \%) \\
\text { Ofloxacin }(43.7 \%) \\
\text { Cefotaxime }(53.1 \%) \\
\text { Levofloxacin }(3.1 \%) \\
\text { Imipenem }(6.2 \%)\end{array}$ \\
\hline P. aeruginosa & $\begin{array}{c}\text { Gentamicin }(95.2 \%) \\
\text { Tetracycline }(90.4 \%) \\
\text { Cefoperazone }(85.7 \%)\end{array}$ & $\begin{array}{c}\text { Amikacin }(4.7 \%) \\
\text { Tobramycin }(14.2 \%) \\
\text { Ofloxacin }(23.8 \%) \\
\text { Imipenem }(14.2 \%) \\
\text { Meropenem }(14.2 \%)\end{array}$ \\
\hline S. aureus & $\begin{array}{c}\text { Penicillin }(73.6 \%) \\
\text { Roxithromycin }(68.4 \%)\end{array}$ & $\begin{array}{c}\text { Cefuroxime }(26.3 \%) \\
\text { Cefazolin }(36.8 \%) \\
\text { Netilmicin }(21 \%)\end{array}$ \\
\hline \multicolumn{3}{|c|}{$\begin{array}{l}\text { Table 2. Antibiotics (Routine and Higher) Showing } \\
\text { Maximum and Minimum Resistance to Organisms }\end{array}$} \\
\hline
\end{tabular}

\begin{tabular}{|cccc|}
\hline Isolates & $\begin{array}{c}\text { No. of } \\
\text { Isolates }\end{array}$ & $\begin{array}{c}\text { ESBL Producers } \\
\text { No (\%) }\end{array}$ & $\begin{array}{c}\text { MBL Producers } \\
\text { No (\%) }\end{array}$ \\
\hline Acinetobacter spp & 32 & $16(50 \%)$ & $0(0 \%)$ \\
Klebsiella spp & 32 & $25(78.12 \%)$ & $0(0 \%)$ \\
Pseudomonas aeruginosa & 21 & $0(0 \%)$ & $12(57.14 \%)$ \\
\hline \multicolumn{3}{|c|}{ Table 3. Percentage of ESBL and MBL Producers in } \\
GNBs Isolated from ET Secretions \\
\hline
\end{tabular}

\begin{tabular}{|ccc|}
\hline Total S. aureus & No. of MRSA (\%) & No. of MSSA (\%) \\
\hline 19 & $5(26 \%)$ & $14(74 \%)$ \\
\hline Table 4. Percentage of MRSA Isolated from & ET Secretions \\
\hline
\end{tabular}

Multi drug resistance (MDR) is the antimicrobial resistance shown by the organism to over two classes of antibiotics. Prevalence of MDR in various GNBs and grampositive cocci (GPC) was studied during which multidrug resistance was reported in acinetobacter spp (84.37\%), klebsiella spp (71.87\%) P. aeruginosa (33.33 \%) and S. aureus 5 (26.31\%). (Figure 1)

Prevalence of ESBL and MBL production in MDR and non MDR isolates was studied that showed MDR isolates were the chief ESBL or MBL producers.

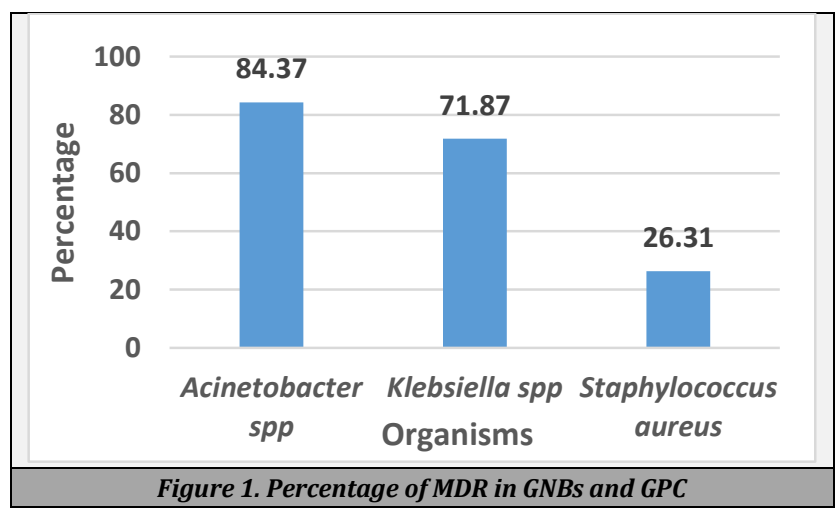

\begin{tabular}{|ccc|}
\hline Organisms & $\begin{array}{c}\text { ESBL or MBL Production } \\
\text { in MDR (\%) }\end{array}$ & $\begin{array}{c}\text { ESBL and MBL Production } \\
\text { in Non MDR (\%) }\end{array}$ \\
Acinetobacter spp & $16(50 \%)$ & 0 \\
Klebsiella spp & $23(100 \%)$ & $2(22.2 \%)$ \\
P. aeruginosa & $7(100 \%)$ & $5(35.71 \%)$ \\
\hline \multicolumn{2}{|c|}{ Table 5. Prevalence of ESBL or MBL Production } \\
in MDR and Non MDR Isolates
\end{tabular}

\section{DISCUSSION}

Lower respiratory tract infection remains the main reason of concern from several decades resulting in high mortality and morbidity rate worldwide. Lower respiratory tract is colonised chiefly by endogenous and exogenous bacteria.

During this present study, seven totally different gramnegative bacteria were isolated. They were acinetobacter spp 32 (27.3\%) klebsiella spp 32 (27.3\%) followed by $P$. aeruginosa 21 (17.6\%), citrobacter spp 11 (9.4\%), Escherichia coli $(7.6 \%)$, enterobacter spp $9(7.6 \%)$ and gram negative non fermenters $3(2.5 \%)$.

In the study by Deepti Chandra et $\mathrm{al}^{6}$ the common organisms were klebsiella species, 11 (32.35 \%) followed by acinetobacter spp, 7 (20.58\%), Pseudomonas aeruginosa, 5 $(14.70 \%)$.

In this present study 38 Gram positive bacteria were isolated, out of which S. aureus 19 / 38 (50 \%) was the foremost predominant organism. Present study correlates with study by Purba Mukherjee and Prativa Biswas ${ }^{7}$ that showed S. aureus (50\%) as the most predominant pathogen.

In this present study antibiotic resistance pattern of gram negative and gram-positive organism was studied. In our study, acinetobacter spp showed maximum resistance to ceftazidime (96.8\%), cefoperazone (93.7\%) and cefazoline $(90.6 \%)$ whereas within the study by Santosh Khanal et al ${ }^{8}$ very high resistance to ofloxacin (80\%) and amikacin (78.2\%) was reported. 
In the present study, klebsiella spp, showed resistance to tetracycline (90.6\%), cefuroxime (87.5\%) and ceftazidime $(84.3 \%)$. Santosh Khanal et $\mathrm{al}^{8}$ in his study reported a really high resistance to amikacin (54.8\%), cefotaxime (78.6\%), ofloxacin (64.3\%) and imipenem (9.5\%). In our study solely $15 \%$ of klebsiella was resistant to amikacin.

Present study showed $P$. aeruginosa was resistant to gentamicin (95.2 \%) and amikacin (80.9\%) which correlates with the study by Azar Dokht $\mathrm{K}$ et al within which resistance was reported to gentamicin (69.7\%), amikacin (68.4\%) and imipenem (60.4\%). Similar findings have been additionally reported from Iran in $2013 .{ }^{9}$

Amongst gram positive bacteria, $S$. aureus showed resistance to penicillin (73.6 \%) and roxithromycin (68.4\%). Study by Regha IR and Sulekha B also reported resistance to penicillin (84.6\%). ${ }^{10}$

In the current study ESBL and MBL production was studied. ESBL production was predominantly seen in klebsiella spp (78 \%) and acinetobacter spp (50 \%) and MBL production was observed in Pseudomonas aeruginosa (57.14 \%). A study by Santosh Khanal et $\mathrm{al}^{8}$ also showed similar findings. ESBL and MBL producing bacteria are increasing public unhealthiness worldwide and mortality rates are increased because of inadequate empirical therapy.

MRSA is a major infectious agent inflicting LRTI and the identification of MRSA carriage is a vital measure to prevent and control these infections in LRTI. The risk factor for the development of LRTI is the settlement of lower airways. In the present study 5 / 19 (26\%) methicillin resistant S. aureus were isolated that correlates with the study by Shrestha RK et al ${ }^{11}$ which shows 6 isolates were MRSA.

Multi drug resistance pattern was studied in gram negative and gram-positive bacteria. Out of total 117 bacteria 74 bacteria were multidrug resistant of which predominant bacteria were acinetobacter spp 27 / 32 (84.37\%) and klebsiella spp 23 / 32 (71.87 \%). Similar findings were also shown by Santosh Khanal et $\mathrm{al}^{8}$ where in acinetobacter spp $(85.4 \%)$ and klebsiella spp (73.8\%) were the predominant MDR GNBs.

Present study shows multi drug resistance in gram positive bacteria. Out of 19 isolates of S. aureus, 5 (26.3\%) isolates of $S$. aureus were multi drug resistant. This is less than the percentage reported by Santosh Khanal et al ${ }^{8}$ in which 6 / 12 (50\%) S. aureus were MDR.

The potential factors enhancing the emergence of resistant bacteria in hospitalised patients might be due to prolonged stay in hospitals, mechanical devices, previous use of broadspectrum antibiotics. The emergence of MDR will be prevented by adopting antibiotic policy worldwide. The emergence of MDR pathogens can be prevented by adopting antibiotic institutional policy and dose de-escalation regimes. ${ }^{12}$

In this present study, prevalence of ESBL and MBL production in MDR and non MDR isolates was studied which showed multi drug resistance was related to either ESBL or MBL production in GNBs.

The importance of ESBL or MBL producing strains lies in the fact that they are difficult to treat because they carry plasmids which confer resistance to many other antibiotics. ${ }^{13}$

The pan drug resistant strains are on the verge of arising. The incidence of ventilator associated pneumonia can be prevented by adopting careful intubation techniques, oral intubation, avoid gastric over-distention, maintaining adequate endo tracheal cuff pressure and efficient tracheal toileting may facilitate in minimising the VAP cases. ${ }^{14}$

\section{CONCLUSIONS}

LRTI remains an important cause of high mortality and morbidity rate worldwide; therefore, identification of the causative agents and their antibiotic susceptibility pattern will play a key role in selecting the suitable antibiotics for clinicians and will improve conditions.

The present study revealed gram negative bacteria as the major pathogens inflicting LRTI; therefore, by performing aseptic measures within the intensive care unit (ICU), the frequency of LRTI can be controlled.

Besides the high degree of antibiotic resistance in hospitals, the major concern is ESBL and MBL in gram negative bacteria. Routine antibiotic susceptibility testing could fail to notice ESBL and MBL producers; therefore, straight forward ways like confirmatory test method may play a very important role in screening the ESBL and MBL producing isolates.

Methicillin resistance in gram positive bacteria also plays a major role in resistance of $S$. aureus. Periodic and statistical analysis of LRTI pathogens and their antibiogram should be carried out in every institution for effective infection management.

Data sharing statement provided by the authors is available with the full text of this article at jemds.com.

Financial or other competing interests: None.

Disclosure forms provided by the authors are available with the full text of this article at jemds.com.

Authors thank the Medical College, for providing the opportunity to perform this study. Authors would also thank the entire staff, colleagues and the laboratory staff of Microbiology Department for their support and immense help during the study.

\section{REFERENCES}

[1] Shin YM, Oh YM, Kim MN, et al. Usefulness of quantitative endotracheal aspirate cultures in intensive care unit patients with suspected pneumonia. J Korean Med Sci 2011;26(7):865-9.

[2] Bajpai T, Shrivastava G, Bhatambare GS, et al. Microbiological profile of lower respiratory tract infections in neurological intensive care unit of a tertiary care centre from Central India. J Basic Clin Pharm 2013;4(3):51-5.

[3] CLSI. Performance standards for antimicrobial susceptibility testing. 22nd Informational Supplement. Wayne, PA: Clinical and Laboratory Standards Institute 2016.

[4] CLSI. Performance Standards for Antimicrobial Susceptibility Testing, M100. 27th Informational Supplement. Wayne, PA: Clinical and Laboratory Standards Institute 2017.

[5] Yong D, Lee K, Yum JH, et al. imipenem-EDTA disk method for differentiation of metallo- $\beta$-lactamase-producing clinical isolates of pseudomonas spp and acinetobacter spp. J Clin Microbiol 2002;40(10):3798-801. 
[6] Chandra D, Laghawe A, Sadawarte K, et al. Microbiological profile and antimicrobial sensitivity pattern of endotracheal tube aspirates of patients in icu of a tertiary care hospital in Bhopal, India. Int J Curr Microbiol App Sci 2017;6(3):891-5.

[7] Mukherjee P, Biswas P.VAP in neonatal sepsis: an ET Tube based microbiological study. ISOR Journal of Dental and Medical Sciences 2017;16(12):41-4.

[8] Khanal S, Joshi DR, Bhatta DR, et al. $\beta$-lactamaseproducing multidrug-resistant bacterial pathogens from Tracheal aspirates of intensive care unit patients at national institute of neurological and allied sciences, Nepal. ISRN Microbiol 2013;2013:847569.

[9] Khosravi AD, Parhizgari N, Montazeri EA, et al. The prevalence of bacteria isolated from endotracheal tubes of patients in golestan hospital, ahvaz, iran and determination of their antibiotic susceptibility patterns. Jundishpur Journal of Microbiology 2013;6(1):67-71.
[10] Regha IR, Sulekha B. Bacteriological profile and antibiotic susceptibility patterns of lower respiratory tract infections in a tertiary care hospital, Central Kerala. International Journal of Medical Microbiology and Tropical Diseases 2018;4(4):186-90.

[11] Shrestha RK, Dahal RK, Mishra SK, et al. Ventilator associated pneumonia in tertiary care hospital, Maharajgunj, Kathmandu, Nepal. Journal of Institute of Medicine 2013;35(3):21-8.

[12] Standard Operative Procedure-Bacteriology. Antimicrobial resistance surveillance and research network. $1^{\text {st }}$ edn. New Delhi, India: ICMR 2015: p. 37.

[13] Nepal R, Basudha S, Joshi DM, et al. Antibiotic susceptibility pattern of gram-negative isolates of lower respiratory tract infection. J Nepal Health Res Counc 2018;16(1):22-6.

[14] Deja M, Spies C. Prevention measures of ventilator associated pneumonia. Crit Care Med 2009;37(1):330-2. 